\title{
Evaluation and management of adolescent idiopathic scoliosis: a review
}

\author{
Ajit Jada, MD, ${ }^{1}$ Charles E. Mackel, JD, ${ }^{2}$ Steven W. Hwang, MD, ${ }^{3}$ Amer F. Samdani, MD, ${ }^{3}$ \\ James H. Stephen, MD, ${ }^{4}$ James T. Bennett, MD, ${ }^{5}$ and Ali A. Baaj, MD ${ }^{1}$
}

1Department of Neurological Surgery, Weill Cornell Medical College, New York, New York; ${ }^{2}$ Department of Neurosurgery, Tufts Medical Center and Floating Hospital for Children, Boston, Massachusetts; ${ }^{3}$ Shriners Hospitals for Children—Philadelphia; ${ }^{4}$ Department of Neurosurgery, University of Pennsylvania; and ${ }^{5}$ Department of Orthopaedic Surgery, Lewis Katz School of Medicine at Temple University, Philadelphia, Pennsylvania

Adolescent idiopathic scoliosis (AIS) is a 3D spinal deformity affecting children between the ages of 11 and 18, without an identifiable etiology. The authors here reviewed the available literature to provide spine surgeons with a summary and update on current management options.

Smaller thoracic and thoracolumbar curves can be managed conservatively with observation or bracing, but corrective surgery may be indicated for rapidly growing or larger curves. The authors summarize the atypical features to look for in patients who may warrant further investigation with MRI during diagnosis and review the fundamental principles of the surgical management of AIS.

Patients with AIS can be managed very well with a combination of conservative and surgical options. Outcomes for these children are excellent with sustained longer-term results.

https://thejns.org/doi/abs/10.3171/2017.7.FOCUS17297

KEY WORDS adolescent idiopathic scoliosis; pediatric; spine; deformity

A DOLESCENT idiopathic scoliosis (AIS) is one of the most commonly treated types of scoliosis. We here summarize the classification, evaluation, and management of AIS and briefly discuss more subtle aspects of clinical care.

\section{Etiology and Pathogenesis}

Adolescent idiopathic scoliosis is a 3D spinal deformity that can involve one or more segments of the thoracolumbar vertebral column, ${ }^{19,61}$ affects children between the ages of 11 and $18,{ }^{27}$ and is of unknown etiology. In the simplest terms, scoliosis is described as lateral curvature of the spine $>10^{\circ}$ with a rotational component of the vertebrae. Scoliosis is assigned to different subgroups based on patient age at onset, disease severity and etiology, and type of curve. ${ }^{27}$ It is further subcategorized as idiopathic versus nonidiopathic. Idiopathic scoliosis is subcategorized as follows: infantile scoliosis ( $0-3$ years of age) ${ }^{33}$ juvenile scoliosis (4-10 years of age), ${ }^{7}$ adolescent scoliosis $(11-18$ years of age), ${ }^{27}$ and adult scoliosis (age $>18$ years). ${ }^{27}$

The exact prevalence of AIS is difficult to estimate based on the current literature. Varying definitions of scoliosis, the different age groups, and the inclusion of curves $<10^{\circ}$ in studies all contribute to this issue. However, in looking at a meta-analysis of current data, one can estimate an annual prevalence of AIS to be $0.47 \%-5.2 \%$ with a female/male ratio of $1.5: 1$ to $3: 1$, increasing with age. 25,27 , 42,54,64 In 2009 the total cost of treating AIS was estimated as \$514 million (\$137 million from Medicaid), ranking second only to appendicitis in children $10-17$ years old..$^{22,60}$

The current literature cites several possibilities for causative mechanisms of AIS: genetics, biomechanical growth modulation, dorsal shear forces and axial rotational instability, uncoupled spinal neuro-osseous growth, postural abnormalities and hindbrain dysfunction, motor control problems, systemic melatonin-signaling pathway deficien-

ABBREVIATIONS AIS = adolescent idiopathic scoliosis; $A P=$ anteroposterior; $A V R=$ apical vertebral rotation; $A V T=$ apical vertebral translation; $C S V L=$ center sacral vertical line; PA = posteroanterior; TLSO = thoracolumbosacral orthosis; VATS = video-assisted thoracoscopic surgery.

SUBMITTED May 20, 2017. ACCEPTED July 6, 2017.

INCLUDE WHEN CITING DOI: 10.3171/2017.7.FOCUS17297. 


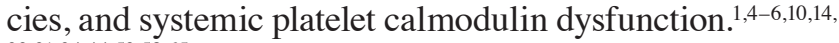
$20,21,24,44,53,58,65$

Various genetic factors have been implicated in the pathogenesis of AIS, but the inheritance of the disorder is unclear. ${ }^{11}$ The literature is inconclusive as to whether the disorder is X-linked, ${ }^{24}$ multifactorial, ${ }^{44}$ autosomal dominant, ${ }^{65}$ or a dominant major gene diallele model. ${ }^{1}$

\section{Clinical Presentation}

The most common presentation of AIS is a disfiguring shape of the back and waistline in a teenage female. Common complaints include experiences with ill-fitting shirts, leaning to one side, or arm friction with the ipsilateral pelvis. A thorough neurological examination is necessary. Particular attention should be paid to reflexes, motor strength, and skin lesions. Clinical leg-length discrepancy should be ruled out as well. Evaluation of the back should focus on shoulder tilt, waistline asymmetry, and palpable masses or skin lesions. The Adams forward bend test is performed to identify rib prominence and is very useful in identifying axial and coronal plane curvatures with corresponding axial rotation. A scoliometer can also be used during this test to clinically quantify the rotation.

Patients with AIS do not usually present with pain or neurological deficits. Radicular symptoms, weakness, bowel or bladder incontinence, and sensory anomalies are exceptionally rare; when they are present, alternative diagnoses should be considered. However, a study by Ramirez et al. ${ }^{41}$ looked at 2442 patients with AIS and noted that $23 \%$ (560 patients) had back pain at the time of presentation and $9 \%$ had back pain during the period of observation. Furthermore, these authors found an association between back pain, an age $>15$ years, skeletal maturity (Risser grade $\geq 2$ ), postmenarchal stage, and a history of injury. ${ }^{41}$ Among the 560 patients with back pain in their study, $9 \%$ had an underlying pathological condition.

Pain, atypical curve patterns, or kyphosis in a patient is predictive of a potential underlying lesion.,2,41 Other authors have suggested that the most common cause of pain in patients with AIS is osteoid osteoma and have recommended bone scans following the standard roentgenograms that are ordered to evaluate scoliosis. ${ }^{41,56} \mathrm{With}$ regard to osteoid osteomas, patients will also report decreasing pain with the use of nonsteroidal antiinflammatory agents. If abnormalities are detected, further workup is necessary to elucidate the nature of the symptoms.

\section{Radiographic Analysis}

Historically, standing posteroanterior (PA), lateral, and side-bending $14 \times 36$-inch cassette radiographs have been the standard for scoliosis evaluation. Standing radiographs are optimal in ambulatory patients because spinal balance and curve magnitude change when a patient is supine. Standing radiographs should include the entire spine as well as the pelvis with clear views of the iliac crests. These views permit determination of the patient's skeletal age as well the global balance of the spine. Advanced imaging such as CT or MRI is reserved for cases in which there are "red flags" (for example, left thoracic curve, kyphosis, pain, or neurological deficits). Lateral radiographs should be reviewed with special attention to the degree of thoracic kyphosis (or in most cases hypokyphosis), lumbar lordosis, and sagittal balance. Cervicopelvic balance and sacropelvic parameters should also be evaluated. The PA films demonstrate the location and extent of scoliosis. The Cobb method is used to measure the degree of this lateral deformity. Computed tomography is not routinely used in the evaluation of AIS in order to limit radiation exposure in this young patient population. Magnetic resonance imaging should be performed in all patients younger than 11 years old with scoliosis $>20^{\circ}$ or in patients with back pain, hyperkyphosis, unusual curves, or an abnormal neurological examination..$^{23,40,51}$

\section{Assessment of Curves and Classifications}

The most common method of measuring curve size is utilizing the Cobb angle on standing $14 \times 36$-inch cassette radiographs in the $\mathrm{PA}$, lateral, and side-bending views. ${ }^{63}$ To calculate the Cobb angle from PA radiographs, a line is drawn along the superior endplate of the upper-end vertebra (vertebra maximally tilted above the apex of the scoliotic curve) and the inferior endplate of the lower-end vertebra (vertebra maximally tilted below the apex of the scoliotic curve). ${ }^{63}$

The pattern of a scoliotic curve is described by the apical vertebra (vertebra at the apex of the curve). It is important to assess the overall or global spinal balance in a patient with scoliosis. For example, if a patient has an isolated thoracic structural curve, he or she may have nonstructural compensatory curves (nonrotated curves) above and below the structural curves to bring the head into alignment over the pelvis. Hence, spinal balance is achieved when the sum of the angles of the compensatory curves equals that of the structural curves. Another important consideration is the pubertal stage of the patient. Puberty lasts 2 years and begins at a bone age of 11 in girls and 13 in boys. This stage is characterized by an "acceleration phase" of rapid growth lasting 2 years and is followed by a steady reduction of growth for 3 years, known as the "deceleration phase." The skeletal maturation of the patient must be followed to evaluate the risk of AIS progression during the acceleration phase; the younger the child, the higher the risk for progression of a scoliotic curve. ${ }^{12}$ Bone age, Tanner classification, stages of puberty, standing and sitting height, arm span, and weight should all be considered when evaluating patients and stages of puberty. ${ }^{49,50,52}$ An early indicator of puberty is ossification of the sesamoid bone of the thumb on anteroposterior (AP) radiographs. ${ }^{12}$ As a general rule, during the acceleration phase of puberty, any spinal curve that increases by $1^{\circ}$ per month is likely to be progressive, while one increasing by $0.5^{\circ}$ can be monitored closely. Any curve increasing by $<0.5^{\circ}$ per month is considered mild. ${ }^{13}$

A saliva-based genetic test (ScoliScore) analyzes 53 single nucleotide polymorphisms to predict the progression of AIS curves and showed promising initial results. ${ }^{59}$ However, independent testing showed less reliable results with a positive predictive value of 0.27 and a negative predictive value of $0.87 .{ }^{47}$ Ongoing research continues to attempt to better define predictive parameters associated 


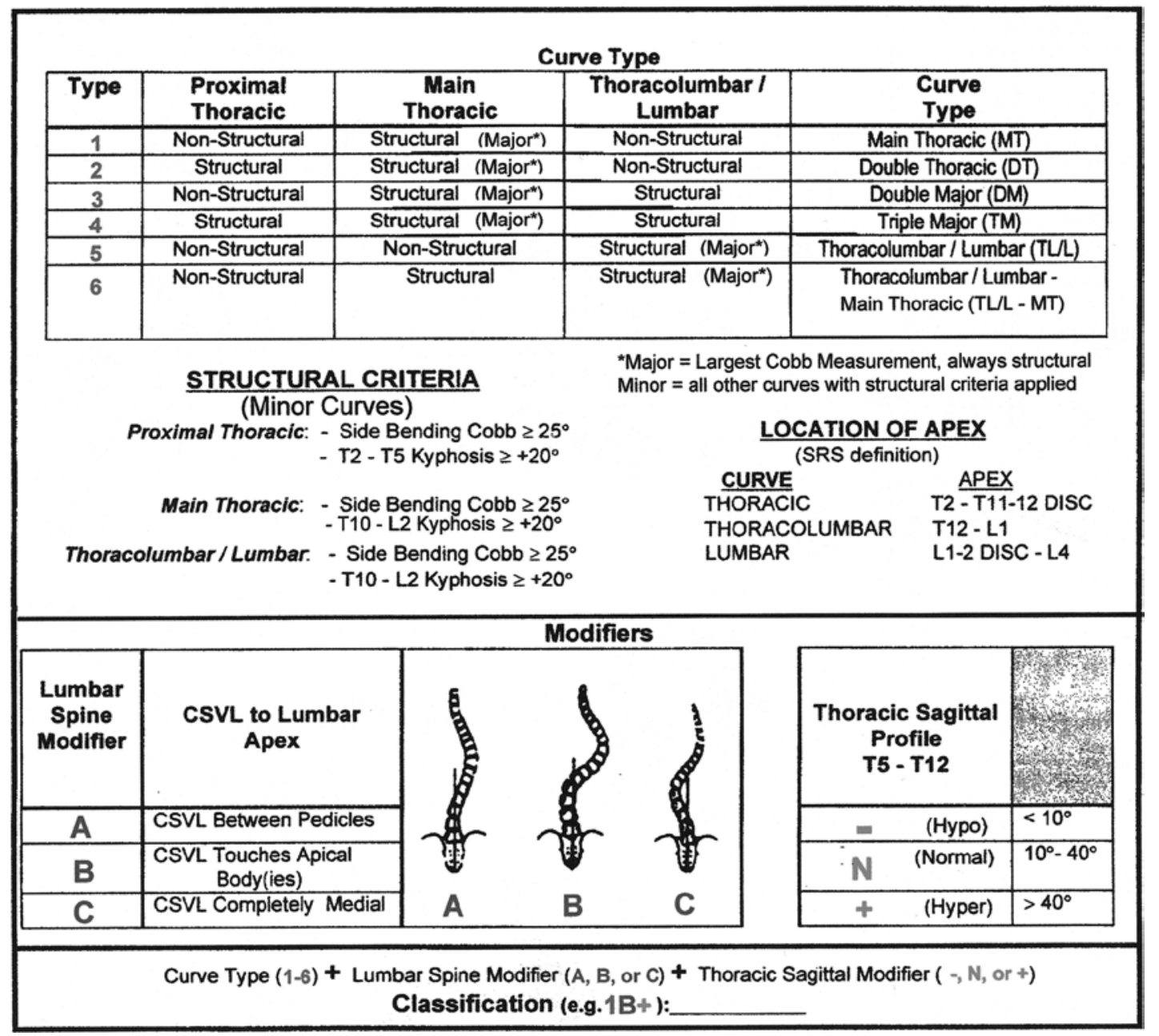

FIG. 1. Lenke classification system. CSVL = center sacral vertical line; SRS = Scoliosis Research Society. Reprinted from Lenke LG, Betz RR, Harms J, Bridwell KH, Clements DH, Lowe TG, et al: Adolescent idiopathic scoliosis: a new classification to determine extent of spinal arthrodesis. J Bone Joint Surg Am 83-A (8):1169-1181, 2001. http://journals.Iww.com/jbjsjournal/pages/ default.aspx. With permission from Wolters Kluwer Health Inc.

with curve progression, but currently no genetic testing is routinely used to predict curve progression.

Surgeons use the Lenke classification system ${ }^{31}$ to classify the types of curves noted in AIS and to determine the extent of arthrodesis necessary to correct scoliosis in this patient population. This system divides curves into 6 types with 3 types of lumbar modifiers (Fig. 1). The curves are described as structural or nonstructural and as main thoracic, double thoracic, double major, triple major, thoracolumbar/lumbar, or thoracolumbar/lumbar-main thoracic. Furthermore, the lumbar spine modifier is applied when a center sacral vertical line (CSVL) is between the pedicles in the lumbar spine curve (A), touches the apical body of the lumbar curve (B), or is medial to the lumbar spine curve $(\mathrm{C}){ }^{31}$

\section{Nonsurgical Treatment}

The primary nonsurgical treatment for AIS is bracing, whose goal is to obviate the need for surgery by limit- ing curve progression. Many scoliotic curves in AIS that are $<20^{\circ}$ can be observed and followed with serial radiographs or clinical examinations at 6-month intervals until skeletal maturity. If the curve is between $25^{\circ}$ and $40^{\circ}$ in a skeletally immature patient with a Risser Grade $0-1$, most would agree that bracing is indicated..$^{32,36,43,46,62}$ While the goal of bracing is to deter further progression of the curve, bracing will not result in curve regression. Two types of braces are used for treating AIS: a thoracolumbosacral orthosis (TLSO) and a cervicothoracolumbosacral orthosis (CTLSO). The former brace type includes the Wilmington, Boston, Lyon, Cheneau, Rigo-Cheneau, Malaga, and SPoRT orthoses. The latter type brace, such as the Milwaukee brace, is typically used for thoracic scoliosis with an apex above T-8, and a TLSO is employed for thoracic scoliosis with an apex at or below T-8. ${ }^{17,53}$ Though opinions in the literature vary, most authors recommend that braces be worn at least 16-20 hours per day with bracing treatment protocols lasting anywhere from 2 to 4 years or until skeletal maturity. ${ }^{26,28,45,55}$ Standing radiographs are 
usually taken at 6-month intervals to assess bracing efficacy or curve progression.

The literature varies on the efficacy of bracing in AIS. Some authors report that Boston bracing is effective in girls with $25^{\circ}-35^{\circ}$ curves..$^{34}$ One Swedish study with a 16-year follow-up concluded that braced patients had no curve progression and that unbraced patients had $6^{\circ}$ of curve progression. ${ }^{9}$ Conversely, a large meta-analysis by Dolan and Weinstein ${ }^{15}$ revealed no significant difference in surgical rates between braced and unbraced patients.

Ideal candidates for bracing are young, have scoliotic curves between $25^{\circ}$ and $40^{\circ}$, are in acceleration growth phases, with a Risser Grade $0-1$ and the goal of delaying surgery to maintain spinal and chest growth. ${ }^{53}$

The most recent and definitive bracing trial was the Bracing in Adolescent Idiopathic Scoliosis Trial (BrAIST), the results of which were published in $2013 .{ }^{60}$ The BrAIST was a multicenter prospective controlled trial comparing bracing to observation in patients with AIS. It included a randomized cohort and preference cohort. The population comprised patients $10-15$ years old with Risser Grades 0 , 1 , or 2 , a Cobb angle of $20^{\circ}-40^{\circ}$ for the largest curve, and no prior treatment for their scoliosis. The bracing group received a rigid TLSO, which was prescribed to be worn 18 hours/day. The trial was stopped early given the efficacy of bracing, which significantly decreased the progression of high-risk curves and was associated with a greater likelihood of reaching skeletal maturity with a major curve $<50^{\circ}$, as compared with observation alone. Furthermore, the likelihood of a successful outcome correlated with the average hours of daily brace wear. ${ }^{60}$ There were important limitations to the study, however. It was not a true randomized controlled design. Treatment preferences limited enrollment in the randomized trial; as a result, the authors added observational patient preference groups, with 116 patients receiving randomly assigned care and 126 receiving patient-directed care, meaning that $71 \%$ of this group chose the bracing treatment. Additionally, not all of the patients wore braces for 18 hours/day, and 27\% stopped using the brace altogether. Furthermore, the association between the duration of brace wear and better outcomes may have been skewed because patients with curves that were likely to progress may have been less inclined to wear the brace. In particular, these curves would be relatively stiff and would resist the corrective measures of bracing. Moreover, the end point of the trial was not curve progression but only curve magnitude and the need for surgery.

There is a need for further research on bracing, and newer studies are analyzing prognostic factors for bracing efficacy. Ogilvie et al. have looked at various genetic markers in AIS as a predictive measure of bracing efficacy. ${ }^{39}$ Using a 30-marker genetic panel, the authors predicted which patients had curves that were likely to be brace resistant ${ }^{39,53}$ Despite initial promising data, recent reviews have demonstrated that methods for predicting curve progression and bracing efficacy are not reliable and cannot be recommended as diagnostic criteria. ${ }^{38}$

\section{Surgical Treatment}

The relative indications for surgery in patients with
AIS are curves $>45^{\circ}-50^{\circ}$ or rapidly progressing curves. The goals of surgery are to correct the deformity and stabilize the spinal curve, typically with instrumentation, while accounting for overall spinal balance. Posterior pedicle screw and rod fixation techniques represent the mainstay of approaches, with anterior approaches reserved for some thoracolumbar curves or anterior releases reserved for severe deformities. Anterior spinal fusion is typically indicated for skeletally immature patients to arrest vertebral growth and prevent a crankshaft deformity, reduce the number of vertebral bodies included in the fusion construct, and increase flexibility for the correction of rigid curves. ${ }^{53}$

For either the anterior or posterior approach, all levels to be included in the fusion are typically exposed. For anterior approaches, discectomies are performed at the intended fusion levels. For posterior approaches, the ligamentum flavum can be resected to allow for greater correction of curves, with or without discectomies, depending on the extent and type of correction required.

For anterior approaches, a thoracic surgeon provides exposure to the anterior chest. From this approach, cortical screws and interbody constructs can be placed. Care must be taken to measure the length of the vertebral cortex in order not to penetrate the contralateral side with the screw. Furthermore, the interbody grafts or cages should be typically placed on the concave side of the scoliosis to facilitate curve reduction. ${ }^{37}$

There is considerable debate in the literature regarding single versus dual rod placement, with dual rod constructs resulting in increased stiffness in torsion and flexion-extension loading. ${ }^{18}$ In a recent retrospective study, Nambiar et al. ${ }^{35}$ analyzed patients undergoing an anterior approach for the correction of AIS. In that multicenter study, patients received either single or dual rod instrumentation via an anterior approach. The authors found no significant differences in postoperative radiographic measurements and functional outcomes between the groups.

With recent advances, video-assisted thoracoscopic surgery (VATS) has been employed for anterior approaches. Reviews of the procedure advocate its use based on superior cosmesis as compared to that obtained with standard approaches and less surgical trauma. However, in addition to increasing operative time, adequate anterior release and curve correction cannot be achieved through the limited VATS corridor. ${ }^{29,64}$

Growth modulation via anterior surgery using internal implants has also been investigated as an alternative surgical option. Vertebral body stapling was developed using the Hueter-Volkmann principle to anchor the convexity of a curve and allow for correction by differential growth along the concavity. However, the indications for vertebral body stapling were quite narrow, encompassing curves ideally between $25^{\circ}$ and $34^{\circ}$ in magnitude. ${ }^{8}$ Ultimately, research based on the staple led to further advances, and current investigations into a vertebral body tether are ongoing. 48

Currently, the most commonly adopted surgical approach is posterior spinal fusion with or without multiple Ponte osteotomies with derotation techniques to provide correction. Pedicle screw instrumentation is used to sta- 

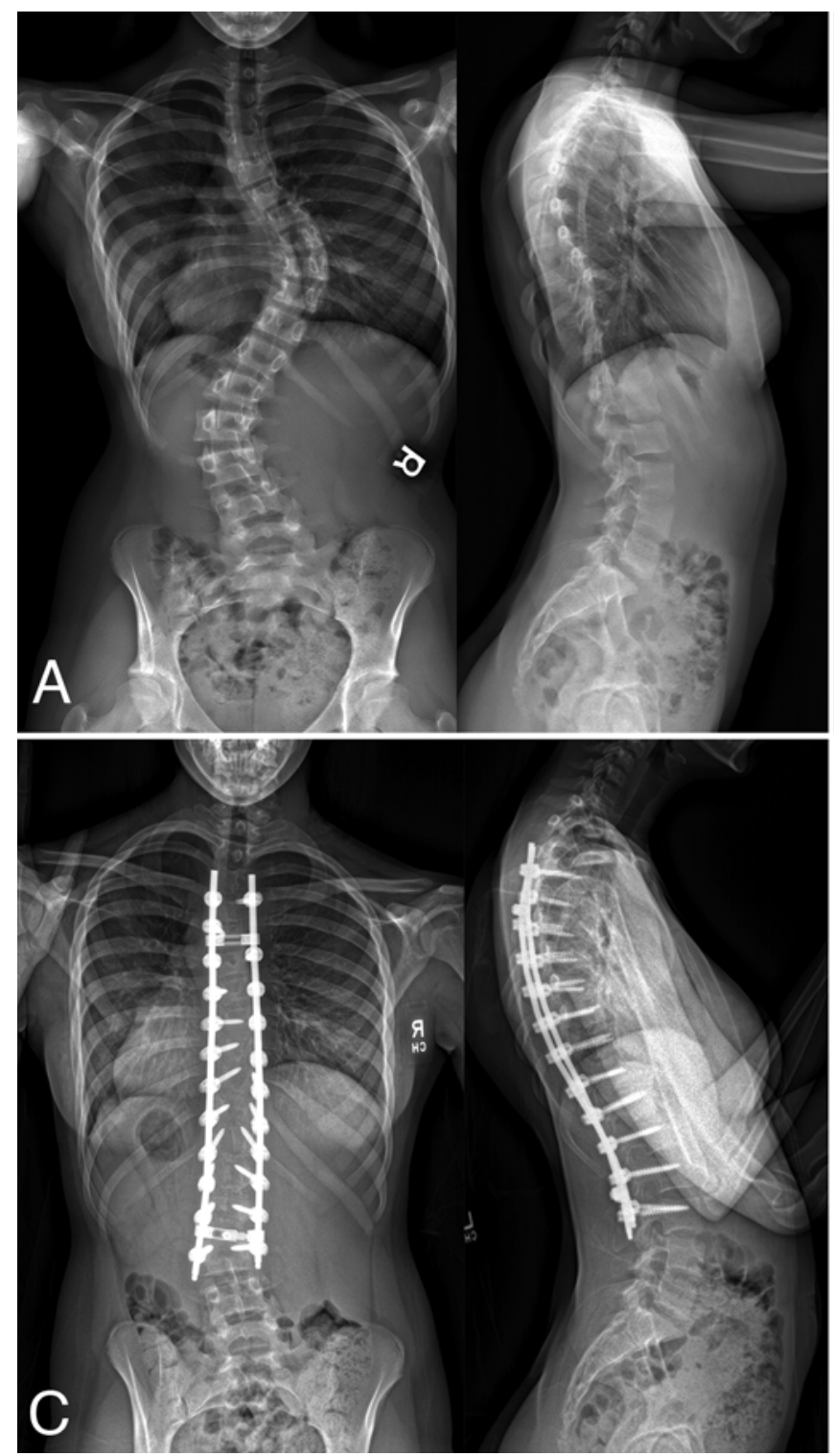

bilize the correction, and arthrodesis is augmented with biologics per surgeon preference.

\section{Surgical Intervention and the Lenke Classification System}

Lenke et al. ${ }^{31}$ have defined the concept of selective fusion, which refers to the fusion of only the structurally major curve. The largest curve is considered structural along with any other curves that do not bend below $25^{\circ}$ or have $>20^{\circ}$ of kyphosis. The selective fusion addresses the structurally major curve while leaving the spinal segments along the minor curves unfused. Proximal thoracic curves range from $\mathrm{T}-2$ to $\mathrm{T}-5$, main thoracic curves from $\mathrm{T}-5$ to $\mathrm{T}-9$, and thoracolumbar curves from T-10 to L-2.

Furthermore, according to the Lenke classification system, there are 2 considerations for inclusion of the lumbar spine in a thoracic fusion construct: 1) flexibility of the

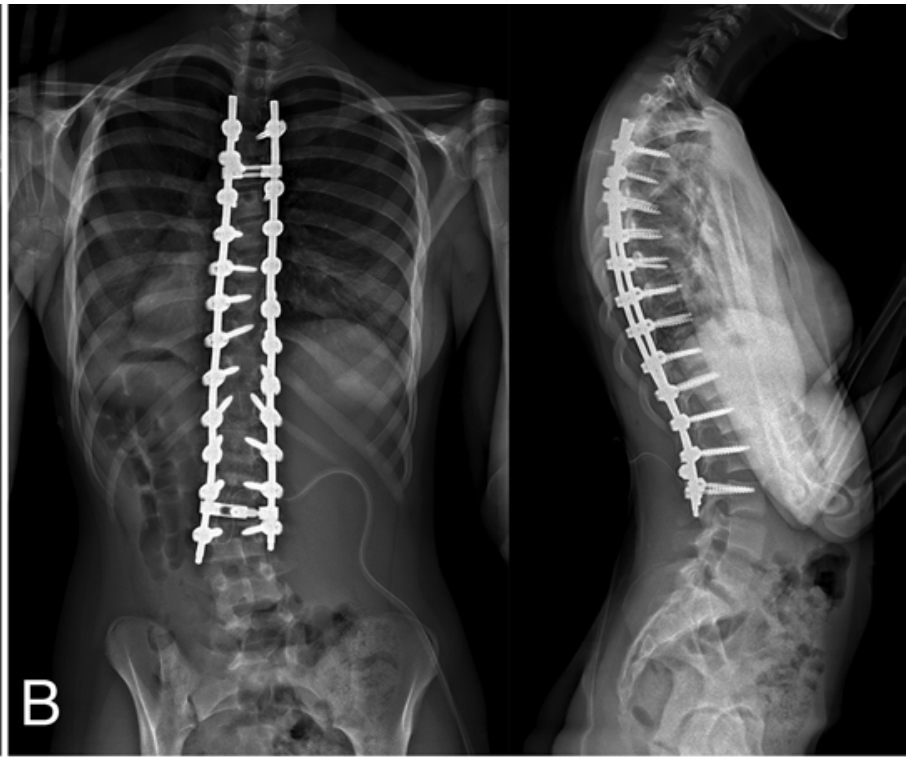

FIG. 2. Case 1. A: AP and lateral radiographs obtained in a 13-year-old girl who was 13 months postmenarche with progressive AIS despite bracing, demonstrating a right thoracic curve of $55^{\circ}$ and left lumbar curve of $48^{\circ}$. B: AP and lateral radiographs demonstrating posterior spinal fusion from T-4 to L-3 with excellent correction of her deformity. C: AP and lateral radiographs obtained at her 6-month follow-up, demonstrating maintenance of correction and intact instrumentation. At that time, the patient had returned to full activities with no complaints.

lumbar curve and 2) the degree of apical vertebral translation (AVT). ${ }^{31,37}$ Flexibility is assessed on a best-bend (to the opposite side) radiograph; if the coronal plane measurement is $<25^{\circ}$, the curve is classified as compensatory and should not be included in the thoracic fusion construct. Next, with respect to the AVT, the larger the translation of the apical vertebra from the CSVL, the more likely it is that a curve is structural and requires inclusion in the fusion levels. ${ }^{31,37}$ Curves assigned lumbar modifier A or B should not be included in the arthrodesis unless there is a kyphosis of at least $+20^{\circ}$ in the thoracolumbar region..$^{30}$

Selective fusion can be performed for Lenke Type $1 \mathrm{C}$, $2 \mathrm{C}$, and $5 \mathrm{C}$ curves. In order for Type 3 scoliosis to have a selective thoracic fusion, the thoracolumbar curve should be minimally rotated, small, and flexible, as denoted on bending lumbar radiographs. For Lenke Type 3C and 6C for which both thoracic and lumbar curves are structural, Cobb angles, AVT, and apical vertebral rotation (AVR) are 


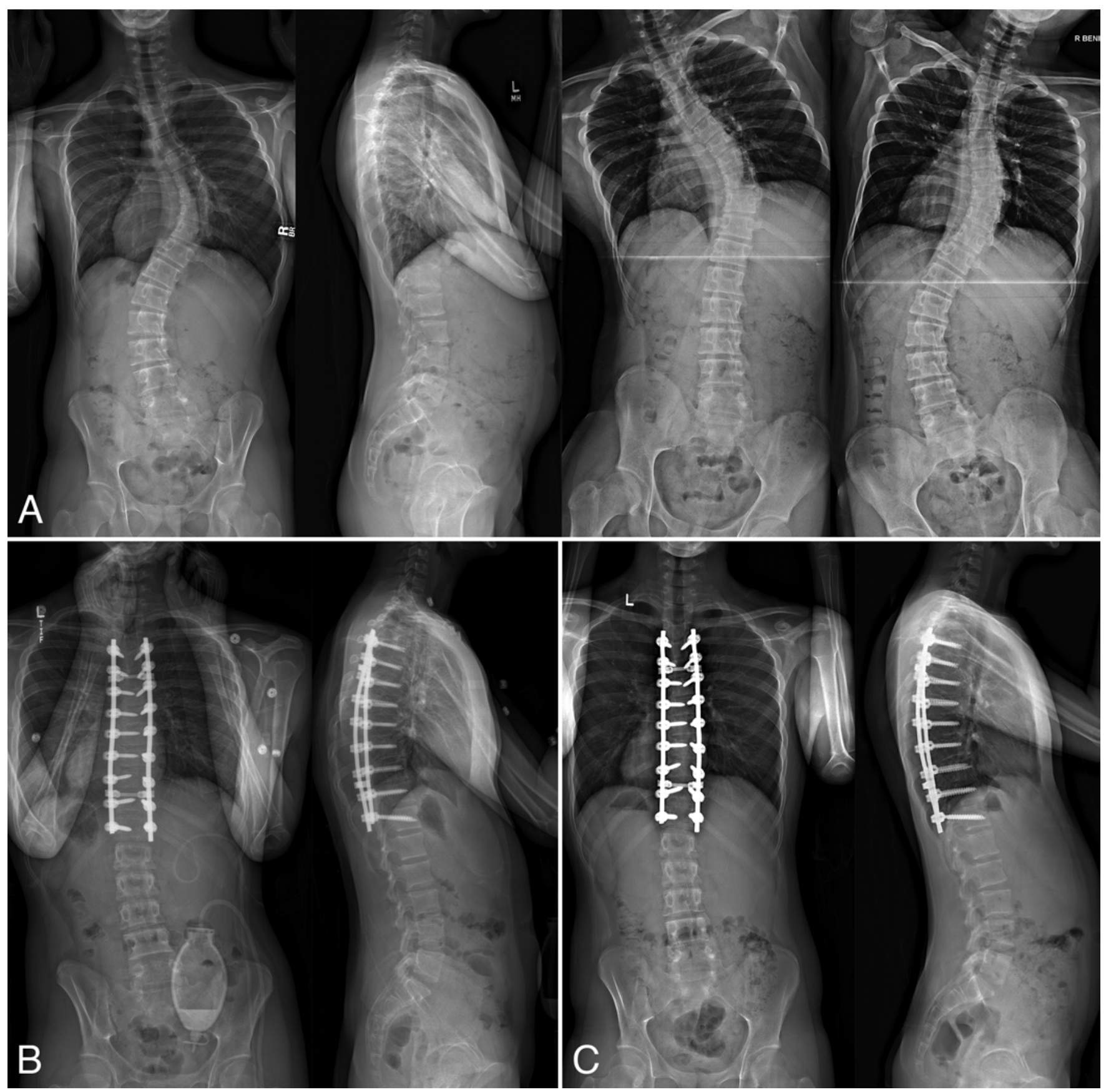

FIG. 3. Case 2. A: AP, lateral, and bending radiographs obtained in a 17-year-old boy with progressive AIS despite bracing, demonstrating a right thoracic curve of $57^{\circ}$ that bent down to $47^{\circ}$ and a flexible $40^{\circ}$ left lumbar curve that bent out to $2^{\circ}$. B: AP and lateral radiographs demonstrating selective posterior spinal fusion from T-4 to T-12 with excellent curve correction of the thoracic and lumbar curves. C: AP and lateral radiographs obtained at his 6-week follow-up, demonstrating maintenance of correction and intact instrumentation.

considered. Selective thoracic fusion in Type 3C scoliosis may be considered if the ratios of Cobb angle, AVT, and AVR measurements for thoracic:thoracolumbar/lumbar curves are $>1.2$. In Type 6C scoliosis, selective thoracic fusion can be employed when the ratios of Cobb angle, AVT, and AVR measurements for thoracic:thoracolumbar/ lumbar curves are $>1.25$. Ratios that approach 1 inher- ently mean that the curves are similar in magnitude and structural in nature, and selective thoracic fusion will fail. ${ }^{30}$

\section{Postoperative Management}

After scoliosis surgery, patients are transferred to a 
surgical intensive care unit or surgical step-down unit. Pain management consists of patient-controlled anesthesia and long-acting oral pain medication. Surgical drains are placed and remain until the output is $<20 \mathrm{ml} /$ day. $\mathrm{Pa}-$ tients are expected to ambulate on postoperative Day 1 or 2. Most patients will not require postoperative bracing. ${ }^{16,57}$

For revision surgery or for patients with prior pseudarthrosis or poor bone quality, postoperative bracing can be used. ${ }^{16}$ In this demographic, patients wear a brace for 6-8 weeks. ${ }^{16}$ At the senior author's institution, patients are able to return to school or work in 2-4 weeks and can resume preoperative activities, with a return to contact sports in 4-6 months. ${ }^{57}$

\section{Illustrative Cases Case 1}

Figure 2A features AP and lateral radiographs obtained in a 13-year-old girl who was 13 months postmenarche with progressive AIS despite bracing. She had a right thoracic curve of $55^{\circ}$ and left lumbar curve of $48^{\circ}$. Bending radiographs had been obtained but were not available. The patient had a main thoracic structural curve and a rigid, structural lumbar curve, which is a Lenke C lumbar spine modifier. Thus, the patient had a Lenke Type 3C curve. Based on the magnitude of the lumbar curve, the AVT, and the Cobb angle ratio for thoracic:thoracolumbar/lumbar curve $<1.25$ and since the lumbar curve was not flexible, a thoracolumbar fusion was performed. Figure 2B shows the final thoracolumbar construct: T4-L3 posterior fusion with instrumentation.

\section{Case 2}

Figure 3A demonstrates AP, lateral, and bending radiographs obtained in a 17-year-old boy with progressive AIS despite bracing. The patient had a right thoracic curve of $57^{\circ}$ that bent down to $47^{\circ}$ and a flexible $40^{\circ}$ left lumbar curve that bent out to $2^{\circ}$. The patient had a main thoracic structural curve and a nonstructural lumbar curve with a Lenke B lumbar spine modifier. Thus, the curve was a Lenke Type 1B curve, and a selective thoracic fusion was employed. The patient underwent a selective T4-12 posterior spinal fusion with instrumentation as depicted in Fig. 3B.

\section{Conclusions}

Adolescent idiopathic scoliosis is a common disease entity facing spinal surgeons who treat pediatric patients. An understanding of the basic principles of evaluation and management is important. Pain symptoms or neurological deficits should alert the surgeon to other diagnoses. Mild $\left(<20^{\circ}\right)$ or moderate $\left(20^{\circ}-40^{\circ}\right)$ curves can be observed or treated with bracing, respectively. More extensive curves need surgical correction and stabilization. The predominant surgical approach is a posterior segmental pedicle screw and rod fixation construct.

\section{Acknowledgments}

We acknowledge the assistance of Carolyn Hendrix and Brian O'Doherty in the preparation of this article.

\section{References}

1. Axenovich TI, Zaidman AM, Zorkoltseva IV, Tregubova IL, Borodin PM: Segregation analysis of idiopathic scoliosis: demonstration of a major gene effect. Am J Med Genet 86:389-394, 1999

2. Barnes PD, Brody JD, Jaramillo D, Akbar JU, Emans JB: Atypical idiopathic scoliosis: MR imaging evaluation. Radiology 186:247-253, 1993

3. Burgoyne W, Fairbank J: The management of scoliosis. Curr Paediatr 11:323-331, 2001

4. Burwell RG: Aetiology of idiopathic scoliosis: current concepts. Pediatr Rehabil 6:137-170, 2003

5. Castelein RM, van Dieën JH, Smit TH: The role of dorsal shear forces in the pathogenesis of adolescent idiopathic scoliosis - a hypothesis. Med Hypotheses 65:501-508, 2005

6. Chu WC, Lam WW, Chan YL, Ng BK, Lam TP, Lee KM, et al: Relative shortening and functional tethering of spinal cord in adolescent idiopathic scoliosis?: study with multiplanar reformat magnetic resonance imaging and somatosensory evoked potential. Spine (Phila Pa 1976) 31:E19-E25, 2006

7. Coillard C, Circo AB, Rivard CH: SpineCor treatment for juvenile idiopathic scoliosis: SOSORT award 2010 winner. Scoliosis 5:25, 2010

8. Cuddihy L, Danielsson AJ, Cahill PJ, Samdani AF, Grewal H, Richmond JM, et al: Vertebral body stapling versus bracing for patients with high-risk moderate idiopathic scoliosis. Biomed Res Int 2015:438452, 2015

9. Danielsson AJ, Hasserius R, Ohlin A, Nachemson AL: A prospective study of brace treatment versus observation alone in adolescent idiopathic scoliosis: a follow-up mean of 16 years after maturity. Spine (Phila Pa 1976) 32:2198-2207, 2007

10. Deacon P, Dickson RA: Vertebral shape in the median sagittal plane in idiopathic thoracic scoliosis. A study of true lateral radiographs in 150 patients. Orthopedics 10:893-895, 1987

11. Dickson RA: The etiology and pathogenesis of idiopathic scoliosis. Acta Orthop Belg 58 (Suppl 1):21-25, 1992

12. Dimeglio A, Canavese F: Progression or not progression? How to deal with adolescent idiopathic scoliosis during puberty. J Child Orthop 7:43-49, 2013

13. DiMeglio A, Canavese F, Charles YP: Growth and adolescent idiopathic scoliosis: when and how much? J Pediatr Orthop 31 (1 Suppl):S28-S36, 2011 (Erratum in J Pediatr Orthop 31:221, 2011)

14. Dobbs MB, Lenke LG, Szymanski DA, Morcuende JA, Weinstein SL, Bridwell KH, et al: Prevalence of neural axis abnormalities in patients with infantile idiopathic scoliosis. J Bone Joint Surg Am 84-A:2230-2234, 2002

15. Dolan LA, Weinstein SL: Surgical rates after observation and bracing for adolescent idiopathic scoliosis: an evidence-based review. Spine (Phila Pa 1976) 32 (19 Suppl):S91-S100, 2007

16. Errico TJ, Lonner BS, Moulton AW (eds): Surgical Management of Spinal Deformities. Philadelphia: Saunders Elsevier, 2009

17. Fayssoux RS, Cho RH, Herman MJ: A history of bracing for idiopathic scoliosis in North America. Clin Orthop Relat Res 468:654-664, 2010

18. Fricka KB, Mahar AT, Newton PO: Biomechanical analysis of anterior scoliosis instrumentation: differences between single and dual rod systems with and without interbody structural support. Spine (Phila Pa 1976) 27:702-706, 2002

19. Ghandehari H, Mahabadi MA, Mahdavi SM, Shahsavaripour A, Seyed Tari HV, Safdari F: Evaluation of patient outcome and satisfaction after surgical treatment of adolescent idiopathic scoliosis using Scoliosis Research Society-30. Arch Bone Jt Surg 3:109-113, 2015

20. Guo X, Chau WW, Chan YL, Cheng JC: Relative anterior 
spinal overgrowth in adolescent idiopathic scoliosis. Results of disproportionate endochondral-membranous bone growth. J Bone Joint Surg Br 85:1026-1031, 2003

21. Guo X, Chau WW, Chan YL, Cheng JC, Burwell RG, Dangerfield PH: Relative anterior spinal overgrowth in adolescent idiopathic scoliosis-result of disproportionate endochondral-membranous bone growth? Summary of an electronic focus group debate of the IBSE. Eur Spine J 14:862-873, 2005

22. HCUP Kids' Inpatient Database (KID): Overview of the Kids' Inpatient Database (KID). Healthcare Cost and Utilization Project (HCUP). Rockville, MD: Agency for Healthcare Research and Quality, 2009 (http://www.hcup-us. ahrq.gov/kidoverview.jsp) [Accessed August 8, 2017]

23. Inoue M, Minami S, Nakata Y, Otsuka Y, Takaso M, Kitahara H, et al: Preoperative MRI analysis of patients with idiopathic scoliosis: a prospective study. Spine (Phila Pa 1976) 30:108-114, 2005

24. Justice CM, Miller NH, Marosy B, Zhang J, Wilson AF: Familial idiopathic scoliosis: evidence of an X-linked susceptibility locus. Spine (Phila Pa 1976) 28:589-594, 2003

25. Kamtsiuris P, Atzpodien K, Ellert U, Schlack R, Schlaud $\mathrm{M}$ : [Prevalence of somatic diseases in German children and adolescents. Results of the German Health Interview and Examination Survey for Children and Adolescents (KiGGS).] Bundesgesundheitsblatt Gesundheitsforschung Gesundheitsschutz 50:686-700, 2007 (Ger)

26. Katz DE, Durrani AA: Factors that influence outcome in bracing large curves in patients with adolescent idiopathic scoliosis. Spine (Phila Pa 1976) 26:2354-2361, 2001

27. Konieczny MR, Senyurt H, Krauspe R: Epidemiology of adolescent idiopathic scoliosis. J Child Orthop 7:3-9, 2013

28. Landauer F, Wimmer C, Behensky H: Estimating the final outcome of brace treatment for idiopathic thoracic scoliosis at 6-month follow-up. Pediatr Rehabil 6:201-207, 2003

29. Lenke LG: Anterior endoscopic discectomy and fusion for adolescent idiopathic scoliosis. Spine (Phila Pa 1976) 28 (15 Suppl):S36-S43, 2003

30. Lenke LG, Betz RR, Bridwell KH, Harms J, Clements DH, Lowe TG: Spontaneous lumbar curve coronal correction after selective anterior or posterior thoracic fusion in adolescent idiopathic scoliosis. Spine (Phila Pa 1976) 24:1663-1672, 1999

31. Lenke LG, Betz RR, Harms J, Bridwell KH, Clements DH, Lowe TG, et al: Adolescent idiopathic scoliosis: a new classification to determine extent of spinal arthrodesis. J Bone Joint Surg Am 83-A:1169-1181, 2001

32. Lonstein JE: Scoliosis: surgical versus nonsurgical treatment. Clin Orthop Relat Res 443:248-259, 2006

33. Mau H: The changing concept of infantile scoliosis. Int Orthop 5:131-137, 1981

34. Nachemson AL, Peterson LE: Effectiveness of treatment with a brace in girls who have adolescent idiopathic scoliosis. A prospective, controlled study based on data from the Brace Study of the Scoliosis Research Society. J Bone Joint Surg Am 77:815-822, 1995

35. Nambiar M, Yang Y, Liew S, Turner PL, Torode IP: Singleversus dual-rod anterior instrumentation of thoracolumbar curves in adolescent idiopathic scoliosis. Eur Spine J 25:3249-3255, 2016

36. Negrini S, Aulisa L, Ferraro C, Fraschini P, Masiero S, Simonazzi P, et al: Italian guidelines on rehabilitation treatment of adolescents with scoliosis or other spinal deformities. Eura Medicophys 41:183-201, 2005

37. Newton PO, O'Brien MF, Shufflebarger HL, Betz RR, Dickson RA, Harms J (eds): Idiopathic Scoliosis: The Harms Study Group Treatment Guide. New York: Thieme, 2010
38. Noshchenko A, Hoffecker L, Lindley EM, Burger EL, Cain CM, Patel VV, et al: Predictors of spine deformity progression in adolescent idiopathic scoliosis: A systematic review with meta-analysis. World J Orthop 6:537-558, 2015

39. Ogilvie JW, Braun J, Argyle V, Nelson L, Meade M, Ward K: The search for idiopathic scoliosis genes. Spine (Phila Pa 1976) 31:679-681, 2006

40. Ouellet JA, LaPlaza J, Erickson MA, Birch JG, Burke S, Browne R: Sagittal plane deformity in the thoracic spine: a clue to the presence of syringomyelia as a cause of scoliosis. Spine (Phila Pa 1976) 28:2147-2151, 2003

41. Ramirez N, Johnston CE, Browne RH: The prevalence of back pain in children who have idiopathic scoliosis. J Bone Joint Surg Am 79:364-368, 1997

42. Reamy BV, Slakey JB: Adolescent idiopathic scoliosis: review and current concepts. Am Fam Physician 64:111116, 2001

43. Richards BS, Bernstein RM, D'Amato CR, Thompson GH: Standardization of criteria for adolescent idiopathic scoliosis brace studies: SRS Committee on Bracing and Nonoperative Management. Spine (Phila Pa 1976) 30:2068-2077, 2005

44. Riseborough EJ, Wynne-Davies R: A genetic survey of idiopathic scoliosis in Boston, Massachusetts. J Bone Joint Surg Am 55:974-982, 1973

45. Roach JW: Adolescent idiopathic scoliosis. Orthop Clin North Am 30:353-365, vii-viii, 1999

46. Rowe D: Introduction. The Scoliosis Research Society Brace Manual. (http://www.srs.org/UserFiles/file/ bracing-manual/section1.pdf) [Accessed August 8, 2017]

47. Roye BD, Wright ML, Matsumoto H, Yorgova P, McCalla D, Hyman JE, et al: An independent evaluation of the validity of a DNA-based prognostic test for adolescent idiopathic scoliosis. J Bone Joint Surg Am 97:1994-1998, 2015

48. Samdani AF, Ames RJ, Kimball JS, Pahys JM, Grewal H, Pelletier GJ, et al: Anterior vertebral body tethering for idiopathic scoliosis: two-year results. Spine (Phila Pa 1976) 39:1688-1693, 2014

49. Sanders JO, Browne RH, McConnell SJ, Margraf SA, Cooney TE, Finegold DN: Maturity assessment and curve progression in girls with idiopathic scoliosis. J Bone Joint Surg Am 89:64-73, 2007

50. Sanders JO, Khoury JG, Kishan S, Browne RH, Mooney JF III, Arnold KD, et al: Predicting scoliosis progression from skeletal maturity: a simplified classification during adolescence. J Bone Joint Surg Am 90:540-553, 2008

51. Schwend RM, Hennrikus W, Hall JE, Emans JB: Childhood scoliosis: clinical indications for magnetic resonance imaging. J Bone Joint Surg Am 77:46-53, 1995

52. Sitoula P, Verma K, Holmes L Jr, Gabos PG, Sanders JO, Yorgova P, et al: Prediction of curve progression in idiopathic scoliosis: validation of the Sanders skeletal maturity staging system. Spine (Phila Pa 1976) 40:1006-1013, 2015

53. Sud A, Tsirikos AI: Current concepts and controversies on adolescent idiopathic scoliosis: Part I. Indian J Orthop 47:117-128, 2013

54. Suh SW, Modi HN, Yang JH, Hong JY: Idiopathic scoliosis in Korean schoolchildren: a prospective screening study of over 1 million children. Eur Spine J 20:1087-1094, 2011

55. Takemitsu M, Bowen JR, Rahman T, Glutting JJ, Scott CB: Compliance monitoring of brace treatment for patients with idiopathic scoliosis. Spine (Phila Pa 1976) 29:2070-2074, 2004

56. Taylor LJ: Painful scoliosis: a need for further investigation. Br Med J (Clin Res Ed) 292:120-122, 1986

57. Vaccaro AR, Baron EM: Operative Techniques: Spine Surgery, ed 2. Philadelphia: Elsevier Saunders, 2012 
58. Veldhuizen AG, Wever DJ, Webb PJ: The aetiology of idiopathic scoliosis: biomechanical and neuromuscular factors. Eur Spine J 9:178-184, 2000

59. Ward K, Ogilvie JW, Singleton MV, Chettier R, Engler G, Nelson LM: Validation of DNA-based prognostic testing to predict spinal curve progression in adolescent idiopathic scoliosis. Spine (Phila Pa 1976) 35:E1455-E1464, 2010

60. Weinstein SL, Dolan LA, Wright JG, Dobbs MB: Effects of bracing in adolescents with idiopathic scoliosis. N Engl J Med 369:1512-1521, 2013

61. Weinstein SL, Hurley R, Snyder A, Martin SP, Lerner M (eds): The Pediatric Spine. Principles and Practice. Philadelphia: Lippincott Williams \& Wilkins, 2001

62. Weiss HR, Negrini S, Rigo M, Kotwicki T, Hawes MC, Grivas TB, et al: Indications for conservative management of scoliosis (guidelines). Scoliosis 1:5, 2006

63. Whittle MW, Evans M: Instrument for measuring the Cobb angle in scoliosis. Lancet 1:414, 1979

64. Wong HK, Hui JH, Rajan U, Chia HP: Idiopathic scoliosis in Singapore schoolchildren: a prevalence study 15 years into the screening program. Spine (Phila Pa 1976) 30:1188-1196, 2005
65. Wynne-Davies R: Familial (idiopathic) scoliosis. A family survey. J Bone Joint Surg Br 50:24-30, 1968

\section{Disclosures}

Dr. Hwang is a consultant for Zimmer Biomet. Dr. Samdani is a consultant for DePuy Synthes Spine, Zimmer Biomet, Stryker, Globus Medical, Ethicon, and Misonix. Dr. Baaj has received royalties from Thieme Medical Publishers and honoraria from AOSpine.

\section{Author Contributions}

Conception and design: Jada, Baaj. Acquisition of data: Jada. Analysis and interpretation of data: Jada. Drafting the article: Jada. Critically revising the article: all authors. Reviewed submitted version of manuscript: all authors. Study supervision: Hwang, Samdani, Baaj.

\section{Correspondence}

Steven W. Hwang, Shriners Hospitals for Children-Philadelphia, 3551 North Broad St., Philadelphia, PA 19140. email: sthwang@ shrinenet.org. 